\title{
Oil Products Quality Improvement by Adsorption Method
}

\author{
KULASH K. SYRMANOVA ${ }^{1}$, ANASTASSIYA Y. KOVALEVA ${ }^{1 *}$, \\ NURZHANY BOTABAYEV ${ }^{1}$, ELVIRA A. BAIBAZAROVA ${ }^{3}$, AINUR K. BEKTURSUNOVA ${ }^{1}$, \\ ZHANAT B. KALDYBEKOVA ${ }^{1}$ and TATYANA V. RIVKINA ${ }^{2}$
}
${ }^{1}$ Auezov South Kazakhstan State University, 160012, Shymkent, Tauke Khan av., 5, Kazakhstan. ${ }^{2}$ Gubkin Russian State University of Oil and Gas, 119991, Moscow, Lenin av., 65, Russia.
${ }^{3}$ M. Kh. Dulaty Taraz State University, 080000, Taraz, Tole Bi st., 60, Kazakhstan. ${ }^{*}$ Corresponding author E-mail: anastasiya2301@ mail.ru

http://dx.doi.org/10.13005/ojc/330133

(Received: December 13, 2016; Accepted: January 01, 2017)

\begin{abstract}
Petroleum takes the leading place in fuel and energy sector. It is a basis of fuel and energy balance of advanced countries economics. Light oil proven reserves reducing is a general trend of modern oil industry development. Almost the entire increase in reserves is due to viscous heavy sour $\mathrm{oil}^{1-2}$. Nowadays quality of the most important oil products is a crucial problem in refinery industry. The problem of oil products quality is connected with their using and operation in engines and machines. Requirements increasing to stability and effective technics maintenance leads to oil products running abilities significant hardening. In order to protect the environment, the task to obtain oil products with improved environmental properties was assigned. Properties of the oil determine the direction and condition of its processing and directly affect the quality of the oil products ${ }^{3-4}$.
\end{abstract}

Keywords: Petroleum, Oil products, Refining, Refinery, Adsorption, Vermiculite, Oil industry.

\section{INTRODUCTION}

Changing oil quality during storage is dependent on their chemical composition, the conditions of storage, transportation and application hardware design features and their surface state of contacting the oil.

Under the influence of external factors in the fuel and oil physical and chemical processes flow. Main physical processes are evaporation, interleaving, contamination by mechanical impurities and water, sedimentation of high melting components during the cooling and accidental mixing in tanks and sequential pumping oil through pipelines of various sorts, such as gasoline and jet fuel. Most of these processes leads to an irreversible change in quality of oil. The main chemical processes are: oxidation, decomposition, polymerization and condensation, corrosion, interaction between individual components and etc ${ }^{5-6}$. 
Besides the classic methods of oil qualities recovery there are also the following -sedimentation, filtration, centrifugation, mixing. The possibility of physical and chemical methods use is increasingly discussing: adsorption, chemical, recovery quality in magnetic and electric field and others.

Adsorption method is a quite widespread. It is known substances selectively absorb certain molecules from a mixture of organic and inorganic compounds of diverse structures. The absorbent material may be solid or liquid, but more widely they are solids (adsorbents). Among the mineral adsorbents most widely used silica gel, which is a hydrated gel of silicic acid $\left(\mathrm{SiO}_{2} \cdot \mathrm{nH}_{2} \mathrm{O}\right)$.

Alumina gels are very similar to silica gel in the part of sorption properties. Alumina gel is a normal aluminum hydroxide mixture and polyhydrates obtained by heat treatment of aluminum hydroxide at temperatures $600-1000^{\circ} \mathrm{C}$. They are characterized by a regular pore structure filled with water at normal temperatures, which can be easily removed by heating. This allows the use of zeolites for the separation and drying agents production. Feature of zeolites is their adsorption cavities interconnected by windows of a certain diameter, transmissive, naturally, only the smaller molecules, but delaying larger.

A significant using as adsorbents (mainly for cleaning liquids of impurities and pigments) consisted of clay natural rocks composed minerals with a regular structure.Clays are undergone to activation by sulfuric or hydrochloric acid treatment.

Vermiculite is a very valuable natural material. Expanded vermiculite, i.e. subjected to heat treatment is applied with a large economic impact in various sectors. Expanded vermiculite does not burn, is chemically inert, durable, biostable, completely explosion and fire safe, ecological, has a beautiful golden color, has ion exchange and sorption properties, a high capacity for absorbing and hold liquids and gases. In South Kazakhstan region there are deposits of it (Kulantau, lirsu, Zhylandy field).

Table 1: Physical-chemical characteristics of Kumkol oil

\begin{tabular}{|c|c|c|c|c|c|}
\hline \multirow{3}{*}{$\begin{array}{l}\text { Indexes } \\
1\end{array}$} & \multicolumn{3}{|c|}{ Well No 3, horizon } & \multirow[b]{3}{*}{5} & \multirow{3}{*}{$\begin{array}{c}\text { Well No } 2 \\
\text { Average } \\
\text { Jurassic } \\
\text { horizon }\end{array}$} \\
\hline & 1 & 2 & 3 & & \\
\hline & 2 & 3 & 4 & & \\
\hline Perforation depth, m & $1078-1093$ & 1205-1209 & $1290-1297$ & 1311-1318 & \\
\hline$\rho_{4}^{20}$ & 0,8215 & 0,8248 & 0,8348 & 0,8208 & \\
\hline Viscosity at $20^{\circ} \mathrm{C}, \mathrm{mm} / \mathrm{s}$ & 9,69 & 14,08 & 22,14 & 8,89 & \\
\hline \multirow[t]{2}{*}{ Temperature, ${ }^{\circ} \mathrm{C}$} & Pour point & 2 & 3,5 & -10 & 5 \\
\hline & Flash point & 20 & 15 & -41 & 0 \\
\hline \multirow[t]{6}{*}{ Content, \% } & Paraffin & 14,78 & 13,2 & 16,52 & 12,7 \\
\hline & Sulfur & 0,37 & 0,43 & 0,38 & 0,41 \\
\hline & Silica gel tar & 8,2 & 6,33 & 6,67 & 7,46 \\
\hline & Pyrobitumen & 1,52 & 2,34 & 0,35 & 0,3 \\
\hline & Vanadium & $0,58 * 10-4$ & $5,0 * 10-4$ & - & - \\
\hline & Nickel & $2,5^{\star} 10-4$ & $3,0 * 10-4$ & & \\
\hline Cocking behavior, \% & & 2,8 & 1,5 & 1,52 & 1,2 \\
\hline Acidity, mg KOH per $1 \mathrm{~g}$ & & 1,0143 & 0,036 & 0,0132 & 0,024 \\
\hline \multirow[t]{2}{*}{ Fractions output, \% } & till $200^{\circ} \mathrm{C}$ & 30,0 & 23,0 & 22,5 & 23,8 \\
\hline & till $350^{\circ} \mathrm{C}$ & 50,0 & 40,0 & 48,8 & 49,4 \\
\hline
\end{tabular}

Viscosity was determined on the apparatus BYH-20. 
Expanded vermiculite after cooling preserves the acquired volume with a very thin layer of air between the piece of mica, resulting in calcined vermiculite has a number of valuable properties - low thermal conductivity, high fire resistance and sound absorption.

\section{MATERIAL AND METHOD}

As a research object the sweet waxy oil of Kumkol oil field was used. Physical-chemical properties of this oil are given in table 1.

\section{RESULTS AND DISCUSSIONS}

Adsorbents using allows to decrease significantly contents of tarry matters and other heterorganic compounds - oxygenic, sulfuric, nitric, metal organic and to remove dissolved and emulsified water from oil products, and also some groups of hydrocarbons and so to change group hydrocarbonic composition of oil products.

In the framework of the research physicochemical studies of oil and oil products, their adsorption treatment by domestic vermiculite sorbent were carried out.

The use of adsorption treatment is most effective way for removing from sewage organic and organometallic compounds to improve the quality of process water for re-use it on the plant and to protect water bodies. This method allows on the post-treatment step to reduce the concentration of organic compounds till 90-99\%. The basic properties of the adsorbents are given in the table 2.

The research of adsorption processes in order to identify the most effective adsorbent for waste water was performed in a laboratory setting of LLP "Petro Kazakhstan Oil Products". $500 \mathrm{ml}$ of the waste water was poured into the tank 1 , where water is mixed with a magnetic stirrer 4 , further flow through the collector 2 fed into the sorption filter 3 . After the filtration water enters into receiving flask 6 . Before The waste water passing adsorbents were hydrated by washing with tap water.

Samples of sewage after biological purification and secondary radial settling tank of water treatment facilities of LLP "Petro Kazakhstan Oil Products" in a volume of $500 \mathrm{ml}$ were pass through filters. The samples were researched, which was taken in different days, so their initial composition varied. In the filtration process effectiveness of the treatment was controlled by samples analyzing $(50 \mathrm{ml})$. Flow rate was $100 \mathrm{ml} / \mathrm{h}$.

The experiment was carried out in dynamic conditions on the laboratory plant. The results of the research are given in the tables 3 . Corresponding sorption kinetics curves $\mathrm{C}=\mathrm{f}(\mathrm{t})$ for the waste water samples are shown in Fig.1-2.

Mineral adsorbents (Fig. 1 and 2) reach a breakthrough of exudation that can be seen in increase the concentration of COD and petroleum products after 4 hours of operation. This can be explained by the fact that apparently runs hydration surface of the mineral material, making it difficult to further adsorption of oil.

Mineral adsorbents operate at low concentrations with comparable efficiency to the carbon adsorbent, purifying wastewater from solutes, but in the presence of colloidal oil impurities adsorbent pores quickly filled and its operation time decreases.

Table 2: Physical properties of the adsorbent

\begin{tabular}{|c|c|c|c|}
\hline \multirow[t]{2}{*}{ Characteristics } & \multicolumn{3}{|c|}{ Adsorbents' samples } \\
\hline & $\begin{array}{c}\text { Hydrocarbonic } \\
\text { Purolat }\end{array}$ & $\begin{array}{l}\text { Kulantau } \\
\text { Vermiculite }\end{array}$ & $\begin{array}{r}\text { Minera } \\
\text { CTU-1 }\end{array}$ \\
\hline Adsorbent's volumeV, ml & 30 & 30 & 30 \\
\hline Adsorbent's mass,m, mg & 20000 & 4000 & 36000 \\
\hline Grain size,d, mm & $1,5-2,6$ & $1,5-2,0$ & $1,0-2,0$ \\
\hline Capacity on oil products, kg/kg & $4-5$ & $4,2-12$ & $4-5,2$ \\
\hline
\end{tabular}


The unique properties of Fluoroplastic-4 are related to its chemical nature and due to the peculiarities of the molecular structure of the perfluoroalkanes. Carbon-fluorine bonds are the most strong among bonds in organic molecules: its rupture energy greater than $100 \mathrm{kkal} / \mathrm{mol}$.

Becouse of its own extremely low "wetting surface tension" Fluoroplastic-4 has very weak adhesion, greatly exceeds the hydrocarbon polymers as water and oil-repellent material.
These properties determine the bandwidth of the hydrophobic Fluoroplastic-4 filter of grains for water coalescence of oil droplets and their detention in the surface layer for dispersions "oil in water". Thus effect was observed on the fluoropolymer, in the form of clearly visible staining oil loading surface, and at very low concentrations of oil in water (10 $\mathrm{mg} / \mathrm{I})$ when the oil was not detected visually in water skipped.

After conducting complex research on the adsorption capacity of Kulantau vermiculite the

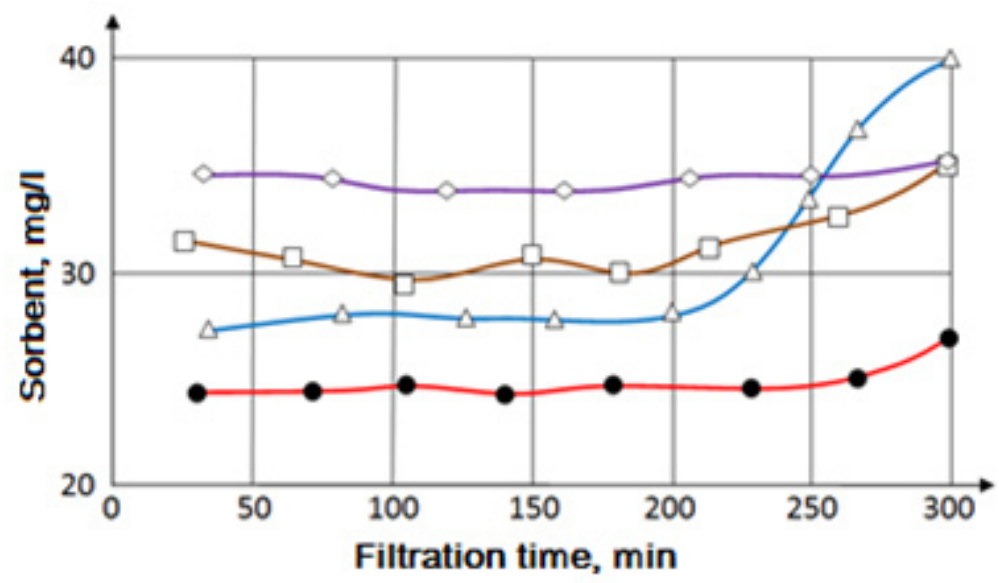

Fig.1: Sorption kinetics curves $C=f(t)$ on a sample No 1 of wastewater

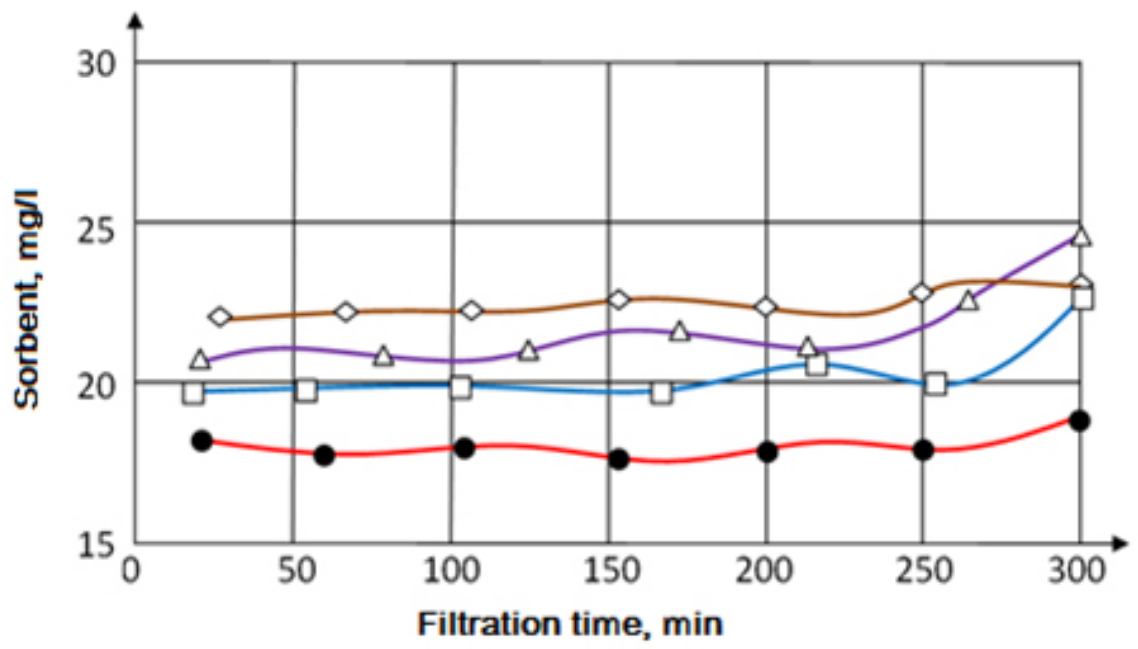

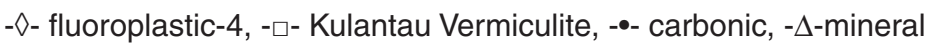

Fig. 2: Sorption kinetics curves $C=f(t)$ on a sample No 2 of wastewater 
Table 3: Adsorption results, for sample 1 of sewage

\begin{tabular}{|c|c|c|c|c|c|c|c|c|c|}
\hline \multirow{2}{*}{$\begin{array}{l}\text { Water } \\
\text { volume } \\
\text { V, MJ }\end{array}$} & \multirow{2}{*}{$\begin{array}{l}\text { Time of } \\
\text { water } \\
\text { flow, } \\
\text { t min }\end{array}$} & \multicolumn{6}{|c|}{$\begin{array}{ccc}\text { CSB-value and NP for water purified at different adsorbents } \\
\text { Carbonic } & \text { Kulantau } & \text { Mineral } \\
\text { purolat } & \text { Vermiculite } & \text { CHU-1 }\end{array}$} & \multicolumn{2}{|c|}{$\begin{array}{l}\text { Fluoroplastic } \\
\quad-4 \text { NP }\end{array}$} \\
\hline & & $\begin{array}{l}\text { CSB, } \\
\mathrm{mg} / \mathrm{l}\end{array}$ & $\begin{array}{l}\mathrm{NP} \\
\mathrm{mg} / \mathrm{l}\end{array}$ & $\begin{array}{l}\text { CSB, } \\
\mathrm{mg} / \mathrm{l}\end{array}$ & $\begin{array}{l}\mathrm{NP} \\
\mathrm{mg} / \mathrm{l}\end{array}$ & $\begin{array}{l}\text { CSB, } \\
\mathrm{mg} / \mathrm{l}\end{array}$ & $\begin{array}{l}\mathrm{NP} \\
\mathrm{mg} / \mathrm{l}\end{array}$ & $\begin{array}{l}\text { CSB, } \\
\mathrm{mg} / \mathrm{l}\end{array}$ & $\begin{array}{l}\mathrm{NP} \\
\mathrm{mg} / \mathrm{l}\end{array}$ \\
\hline 50 & 30 & 24,84 & 2,45 & 31,82 & 4,16 & 27,13 & 3,25 & 33,82 & 5,12 \\
\hline 100 & 60 & 24,36 & 2,65 & 30,73 & 3,93 & 27,24 & 3,37 & 33,58 & 5,22 \\
\hline 150 & 90 & 24,88 & 2,56 & 30,54 & 4,36 & 27,47 & 3,28 & 33,68 & 5,34 \\
\hline 200 & 120 & 25,01 & 2,7 & 29,34 & 3,85 & 27,64 & 3,34 & 33,59 & 5,47 \\
\hline 250 & 150 & 25,35 & 2,35 & 30,56 & 4,42 & 27,86 & 3,42 & 32,95 & 5,49 \\
\hline 300 & 180 & 25,07 & 2,64 & 29,87 & 5,02 & 27,7 & 3,28 & 33,24 & 5,37 \\
\hline 350 & 210 & 25,39 & 3,04 & 30,43 & 4,95 & 28,42 & 3,52 & 33,56 & 5,29 \\
\hline 400 & 240 & 25,22 & 3,16 & 31,01 & 5,11 & 30,94 & 4,31 & 33,11 & 5,41 \\
\hline 450 & 270 & 26,29 & 3,36 & 31,65 & 5,34 & 35,83 & 4,98 & 33,57 & 5,56 \\
\hline 500 & 300 & 27,98 & 3,89 & 33,76 & 5,71 & 39,87 & 6,79 & 33,76 & 5,51 \\
\hline
\end{tabular}

problem of the technical application of the results obtained in the studies was solved. Experiments were conducted in which amount of Fluoroplastic-4 was varied, studying the influence of this parameter on the efficiency of cleaning.

The results showed that the removal of oil efficiently flows at loadings of up to $15 \mathrm{ml}$ per $500 \mathrm{ml}$ of water is effective. Under the conditions of the plant waste water treatment plants filter loading should be not less than $10 \mathrm{~kg}$ per $1 \mathrm{~m}^{3}$ of water to be treated.

The idea to combine coalescing ability of Fluoroplastic-4 with efficiency of adsorbents to remove dissolved impurities was carried out by in the laboratory. For this purpose, a filter column with two layers was used: Fluoroplastic-4 and adsorbent - Kulantau vermiculite, in a volume ratio of 1:4.

To determine the dynamic filter capacitance model oily water was passed through the sample under research. The oil content at the column outlet was monitored as previously described.
The initial concentration of oil $30 \mathrm{~g} / \mathrm{I}$, significantly higher than the average values of waste water LLP "PetroKazakhstan Oil Products".

\section{CONCLUSION}

The research have shown that despite the relatively high efficiency of water purification from impurities by filtration through a Fluoroplastic-4 oil loading can increase the degree of purification only by using adsorbents.

Mineral adsorbents differ from coal higher mechanical stability, which is especially important for periodically changing environment (head) of water transmission in the system of sewage treatment plants of refineries.

The research have shown that in order to combine the advantages of mineral adsorbents and coalescing properties of Fluoroplastic-4, combined filters must be used, consisting of layers of Fluoroplastic-4 and vermiculite absorbent. 


\section{REFERENCES}

1. Gelperin N.I. Basic processes and apparatuses of chemical technology. Moscow. 2011, 412.

2. Kasatkin A.G. Basic processes and apparatuses of chemical technology. Moscow. 2003, 752.

3. Greg S.; Sing K. Adsorption, surface, porocity. Moscow. 2010, 407.

4. Kalyanov N.N. Vermiculite, its properties, technology and application. Perlite and Vermiculite.2004, 110-123.

5. Iskritski N.A. Economics and perspectives of vermiculite using. Science Leningrad Addition. 2005, 152.

6. Gorelik S.S.; Rastorguyev L.N.; Skakov U.A. $\mathrm{X}$-ray and electron-optical analysis. Moscow. 2000, 252. 